\title{
LOGICAL AND PROBABILISTIC METHOD FOR RISK MANAGEMENT IN SOCIO-ECONOMIC SYSTEMS
}

\author{
Vasily Karasev $^{1}$, Ekaterina Karaseva² \\ IPME RAS, Intelligent Integrated Systems of Automated Designing Laboratory ${ }^{1}$ \\ Saint-Petersburg State University of Aerospace Instrumentation, Institute of Business Technologies \\ Department of Information Technologies in Business ${ }^{2}$
}

\begin{abstract}
In this paper we research the application of logical and probabilistic method to manage risk in socioeconomic systems. Logical and probabilistic method is widely used for estimation of reliability and safety in structural complex technical systems. Authors have applied this method to estimate and analyze risk in some practical applications in economics and business. Based on risk scenario as tree of events, logics and probabilistic functions, this approach provides exact quantitative estimation of risk, risk analysis and decision-making procedures. Some promising results were obtained in banking industry and security portfolio management but application of the method has some features.
\end{abstract}

Keywords: logics, probability, management, risk, database, knowledge base, system, identification.

\section{INTRODUCTION}

Logical and probabilistic (LP) method has long history. As early as $1847 \mathrm{G}$. Boole published paper entitled "The Mathematical Analysis of Logic", the first work about symbolic logic. This work began mathematical logic. Later, in 1886 P.S. Poretsky invented logical and probabilistic analysis [1]. In 1917 S.N. Bernstein applied Boole's axiomatic for casual events [10]. A.N. Kolmogorov suggested axiomatic for probability theory in 1929 [11]. In 1939 V.I. Glivenko generalized axiomatic of logic, event and probability [12]. Glivenko proved, for reliability concept we can apply axiomatic of set and measure. Based on above works, in 1959 I.A. Ryabinin developed LP method for estimation and analysis of reliability in complex technical systems [5].

Construction of LP risk models is performed in three stages:

1. Structural risk model or risk scenario (tree of events) is assembled, i.e. casual events and links between them are determined. There are initiating events (lowest level) and derivative events;

2. Logical risk model is constructed under structural risk model. Arguments of logical function correspond to events $(1$ - event appeared, 0 - event not appeared);

3. Transition from logical risk model to probabilistic risk model is performed. Using probabilistic model we can calculate probabilities of derivative events if we know probabilities of initiating events.

In technical systems LP-models are very different [5]. They can correspond to real structure of elements (electric circuit) or they can be a scenario of danger evolution (accident at nuclear power station). Also, there are monotonous LP models (series-parallel connection of elements) or not-monotonous (bridge circuit, tree of events with repeated events) [5, 6]. Models have various complexity and logical connections OR, AND, NOT.

But often it's difficult to determine probabilities of initiating events because large accidents are rare and statistical data volume is small.

In the contrary, in economics and business, risk is usual and widespread phenomenon. Many financial institutions and banks are working under risk conditions. There is good statistics with homogeneous outcomes and we can obtain probabilities of initiating events.

Statistical data is accumulated in tabular databases (DB) which are used for drawing of graphs and figures, making classification and clustering of objects, or, respectively, states of system, derivation of regressions and forecast with use of machine learning tools, which is important part of artificial intelligence and a way to develop self-learning algorithms [7].

In work we are studying the application logical and probabilistic method for estimation, analysis and management of risk and efficiency in socio-economic 
systems. To decide the problem, DB is transformed into knowledge base $(\mathrm{KB})$ as a system of LP risk models for analysis and management of risk.

Typical databases have the feature: in some DBs (credit risk in bank, turnover of the restaurant) the efficiency of states (credits, profit of company) is known (success/default); in other DBs (security portfolio) the efficiency of states (yield of portfolio) is calculated. Respectively, aims of management are formulated differently.

\section{LP RISK MODEL CONSTRUCTION}

Usually, tabular DB contains statistical data about similar objects or states of the system. In table, a number of columns can be within $2-100$ and a number of strings can be within 100 - 1000. Values (parameters) in each cell can be qualitative or quantitative, discrete or continuous [6].

To avoid complexity due to infinite number of values, let change presentation DB with substitution of parameters by their grades (numbers of intervals). Efficiency parameter $E$ adopts the value from set $\left\{E_{l}\right.$, $\left.\ldots, E_{r}, \ldots, E_{m}\right\}$. Parameter $E$ depends on $A_{l}, \ldots, A_{j}, \ldots$, $A_{n}$. Variable $A_{j}$ adopts values (grades) from set $\left\{A_{j l}\right.$, ..., $\left.A_{j r}, \ldots, A_{j N j}\right\}$.

Statistical data are presented by table, where every string $i$ looks like

where:

$$
A_{1, r 1}^{i}, A_{2, r 2}^{i}, \ldots, A_{j, r j}^{i}, \ldots, A_{n, r n}^{i}, E_{r}^{i},
$$

$$
\begin{aligned}
& i \in\{1,2, \ldots, N\} ; r \in\left\{1,2, \ldots, N_{E}\right\} ; r_{1} \in\left\{1,2, \ldots, N_{1}\right\} ; \\
& r_{2} \in\left\{1,2, \ldots, N_{2}\right\} \ldots, r_{j} \in\left\{1,2, \ldots, N_{j}\right\} ; \ldots ; r_{n} \in\left\{1,2, \ldots, N_{n}\right\}
\end{aligned}
$$

Let enter casual events (table 1) and designate them as logical variables. Event $Z_{j r}$ is: the variable $A_{j}$ for any string $i$ adopts value $A_{j r} \equiv Z_{j r} ; A_{j}=A_{j r}$, probability of this event is $P\left(Z_{j r}\right)=P\left(A_{j}=A_{j r}\right)$. Event $Y_{r}$ is: variable $E$ adopts for any string $i$ value $E_{r}$ : $Y_{r}=E_{r}$, probability of events is $P\left(Y_{r}\right)=P\left(E=E_{r}\right)$. We are designating logical variables to events $Z_{j r}, j=1, \ldots$, $n ; r=1, \ldots, N_{j}$ and $Y_{r}, r=1, \ldots, N_{y}$.

Events $Z_{1}, \ldots, Z_{j}, \ldots, Z_{n}$ and $Y$ include groups of incompatible events:

$$
Z_{j}=Z_{j 1}, \ldots Z_{j r}, \ldots Z_{j N p} j=1,2, \ldots n ; Y=Y_{1}, \ldots Y_{r}, \ldots Y_{N y}
$$

So, every event-parameter can take a value from finite set of events-grades which form group of incompatible events (GIE). (table 1).

Table 1 .

States, events and logical variables

\begin{tabular}{|c|c|c|c|c|c|c|}
\hline State & $\begin{array}{c}\text { Event, } \\
Z_{1}\end{array}$ & $\cdots$ & $\begin{array}{c}\text { Event, } \\
Z_{j}\end{array}$ & $\ldots$ & $\begin{array}{c}\text { Event, } \\
Z_{n}\end{array}$ & $\begin{array}{c}\text { Event, } \\
Y_{r}\end{array}$ \\
\hline 1 & $Z^{l}{ }_{1 r l}$ & & $Z_{j r j}^{j}$ & & $Z^{l}{ }_{n r n}$ & $Y_{r y}^{l}$ \\
\hline$\ldots$ & $\ldots$ & & $\ldots$ & & $\ldots$ & $\ldots$ \\
\hline$i$ & $Z^{i}{ }_{1 r l}$ & & $Z_{j r j}^{i}$ & & $Z_{n r n}^{i}$ & $Y_{r y}^{i}$ \\
\hline$\ldots$ & $\ldots$ & & $\ldots$ & & & \\
\hline$N$ & $Z^{N}{ }_{1 r l}$ & & $Z^{N_{j r j}}$ & & $Z^{N}{ }_{n r n}$ & $Y_{r y}^{N}$ \\
\hline
\end{tabular}

In risk scenario events-parameters are connected by logical connections $O R, A N D$.
Largest number of various states (various objects) is equal to:

$$
N_{\max }=N_{1} \cdot N_{2} \cdot \ldots \cdot N_{j} \cdot \ldots \cdot N_{n},
$$

where: $N_{l}, \ldots, N_{j}, \ldots, N_{n}$ are numbers of grades in indicators.

Logical risk function for failure of state $Y$ is:

$$
Y=Z_{1} \vee Z_{2} \vee \ldots \vee Z_{j} \vee \ldots Z_{n},
$$

where $Z_{1}, Z_{2}, \ldots, Z_{n}$ are logical variables for parameters. Logical function $Y$ means state failure and give the sense of influence parameters $Z_{1}, \ldots, Z_{n}$ on failure of event $Y$.

Logical risk function in orthogonal form is:

$$
Y=Z_{1} \vee Z_{2} \overline{Z_{1}} \vee Z_{3} \overline{Z_{2}} \overline{Z_{1}} \vee \ldots
$$

Orthogonality means: multiplication any two logical items in (3) is equal to 0 . This allows make transition from logics to arithmetic and write probabilistic function of failure:

$$
P(Y=0)=P_{1}+P_{2}\left(1-P_{1}\right)+P_{3}\left(1-P_{2}\right)\left(1-P_{1}\right)+\ldots,
$$

where $P_{j}=P\left\{Z_{j}\right\}$ is a probability of event $Z_{j}$ leads to failure $Y$. For every state in formula (4) the probability of corresponding event-grade $Z_{j r}$ from GIE is placed instead event $Z_{j}$ probability. Probabilities of events-grades are determined by method of identification under statistical data from DB $[6,8]$.

According to (2), the system of logical equations (KB) based on DB (table 1) is written so:

$$
\left\{\begin{array}{l}
Z^{1}{ }_{1 r 1} \vee \ldots \vee Z^{1}{ }_{j r i} \vee \ldots \vee Z_{n r n}^{1}=Y_{r y}^{1} \\
\ldots \ldots \ldots \ldots \\
Z^{i}{ }_{1 r 1} \vee \ldots \vee Z^{i}{ }_{j r i} \vee \ldots \vee Z_{n r n}^{i}=Y_{r y}^{i} \\
\ldots \ldots \ldots \ldots \\
Z^{N}{ }_{1 r 1} \vee \ldots \vee Z^{N}{ }_{j r i} \vee \ldots \vee Z_{n r n}^{N}=Y_{r y}^{N} .
\end{array}\right.
$$

For (5), based on (4), the system of probabilistic equations is:

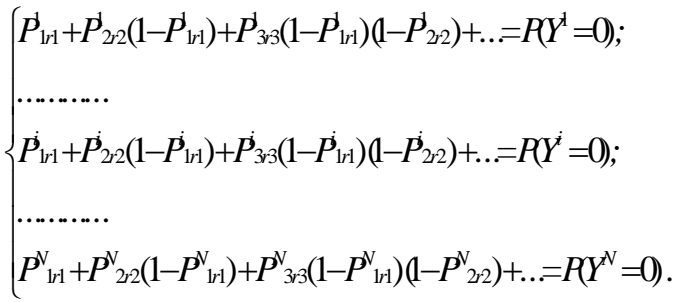




\section{CREDIT RISK MANAGEMENT}

Credits of individuals are described by 20 parameters, every parameter has from 2 to 11 grades [9]. Credit default due to concrete parameter or grade is casual event-parameter or event-grade. Eventsgrades of every parameter form a GIE. Events lead to credit default with certain probability. Risk scenario of credit default is stated so: default occurs, if any one, or two, or three, ..., or all events-parameters occur.

Logical risk model of credit's default:

$$
Y=Z_{1} \vee Z_{2} \vee \ldots \ldots \vee Z_{n}
$$

Logical risk model of credit's default in equivalent orthogonal form:

$$
Y=Z_{1} \vee Z_{2} \overline{Z_{1}} \vee Z_{3} \overline{Z_{2}} \overline{Z_{1}} \vee \ldots
$$

Probabilistic risk model of credit's default:

$$
P=P_{1}+P_{2} Q_{1}+P_{3} Q_{1} Q_{2}+\ldots
$$

where $P_{1}, P_{2}, \ldots, P_{n}-$ are probabilities of credit's default as a result of occurrences of eventsparameters; $Q_{1}=1-P_{1}, \quad Q_{2}=1-P_{2}, \ldots, \quad Q_{n}=1-P_{n}, \quad$ In formula (8) values of probabilities for events-grades are placed. Credits in database are classified by risk value (probability of default) (fig. 1).

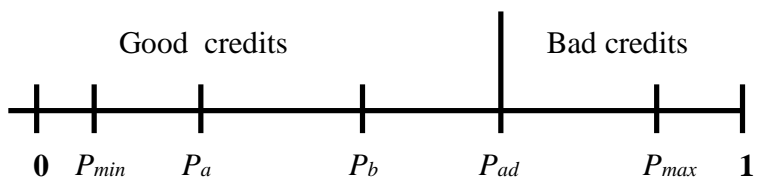

Figure 1. Credit classification scheme

The identification (learning) of the LP credit risk model is performed on the statistical data [8] and the goal of this procedure is to calculate probabilities of the events-grades $P_{j r}, \quad r=1, \ldots, N_{j}, \quad j=1, \ldots, n$, the admissible credit risk $P_{a d}$ and risks $P_{i}, i=1,2, \ldots, N$ of credits. The condition $P_{i}>P_{a d}$ let us distinguish the following types of the credits: $N_{g g}-$ are "good" both the LP-model and statistics; $N_{g b}$ - are "good" by the LP-model but "bad" by statistics; $N_{b g}-$ are "bad" by the LP-model but "good" by statistics; $N_{b b}-$ are "bad" both the LP-model and statistics.

Transition from $\mathrm{DB}$ to $\mathrm{KB}$ and $\mathrm{LP}$ credit risk model allows to decide following problems $[6,9]$ :

1. Quantitative estimation of risk for every credit and average risk of a bank;

2. Quantitative estimation of contribution of credit's parameters and their grades in risk of every credit and average credit risk of a bank;

3. Determination of admissible risk proceed from condition of given asymmetry of recognition of "good" and "bad" credits.
4. Exception outdated and incorrect credits from bank's statistics, used for credit risk model learning,;

5. Re-learning of probabilistic risk model after the forming of signal part of finalized credits.

Use of LP model in credit risk estimation has following advantages:

- increasing of accuracy in risk estimation for "good" and "bad" credits in 1,5 - 2,5 times more, and, correspondingly, reduce of bank losses;

- increasing robustness (stability) of classification of credits on "good" and "bad" seven times more in comparison with models on basis of neural networks;

- effective management of crediting process in bank by changing of parameters both LP risk model and monitoring technology.

\section{OPERATIONAL RISK MANAGEMENT}

In comparison with financial risks, operational risk is non-financial and realized in events: power system failure, personnel mistake, flood, earthquake or terrorism actions. Problem of estimation and identification of operational risk in bank is very complex. Operational risk is caused by different factors and difficult for formalization and modeling.

Basel Committee [10] divides bank's activity by 8 business lines. In advanced approach [10] every business line is considered separately. In every business line seven kinds of unfavorable operational risk events are considered: internal fraud $Z_{l}$; external fraud $Z_{2}$; personnel policy and labor safety $Z_{3}$; clients, products and business practice $Z_{4}$; physical damage of assets $Z_{5}$; faults in business and system failures $Z_{6}$; execution, delivery and process control $Z_{7}$. These are derivative events. Every event from $Z_{1}, \ldots, Z_{7}$ is caused by concrete elementary events, i.e. initiating events. Initiating events are considered as independent casual events. In overall, 98 events were entered. Final derivative event $Y$ is possible losses at business line. The number of initiating events for every business line is equal to 70 and they are the same by description but their probabilities for every business line will be different. Logical variable corresponds to every initiating event. This variable takes values 1 or 0 (events will occur or not) with the certain probability. Initiating events have probabilities of occurrence. These probabilities can be obtained from statistical data accumulated during last period of bank's.

Structural, logical and probabilistic risk models are constructed for every business line [11].

As example, let consider first business line of bank (Corporate Finance). We construct the structural model and write the logical function of risk for seven kinds of unfavorable events $Z_{1}, Z_{2}, Z_{3}, \ldots Z_{7}$.

Risk scenario is formulated so: event $Y_{1}$ (losses at first business-line) will occur if event $Z_{1}$ or event $Z_{2}$, 
or $Z_{3}, \ldots$, or $Z_{7}$ will occur. By other words, $Y_{1}$ will occur if, at least, any one event from set $Z_{1}, \ldots, Z_{7}$, will take place, or any combination of events, or all of them will occur at the same time (probability of such variant is very small but not equal to 0 ). Let $Z_{1}, \ldots, Z_{7}$ are logical variables, every $Z_{j}, j=1,2, \ldots, 7$ is equal 1 (if events took place) or equal to 0 (in opposite case) with some probability.

Logical operational risk model for seven kinds of unfavorable events $Z_{1}, Z_{2}, \ldots, Z_{7}$ of operational risk for first business line is written in disjunctive normal form by following way:

$$
Y_{1}=Z_{1} \vee Z_{2} \vee Z_{3} \vee Z_{4} \vee Z_{5} \vee Z_{6} \vee Z_{7}
$$

In order to obtain probabilistic model we have to write equation (9) in orthogonal disjunctive normal form:

$$
\begin{gathered}
Y_{1}=Z_{1} \vee Z_{2} \bar{Z}_{1} \vee Z_{3} \bar{Z}_{1} \bar{Z}_{2} \vee Z_{4} \bar{Z}_{1} \bar{Z}_{2} \bar{Z}_{3} \vee \\
Z_{5} \bar{Z}_{1} \bar{Z}_{2} \bar{Z}_{3} \bar{Z}_{4} \vee Z_{6} \bar{Z}_{1} \bar{Z}_{2} \bar{Z}_{3} \bar{Z}_{4} \bar{Z}_{5} \vee \\
\vee Z_{7} \bar{Z}_{1} \bar{Z}_{2} \bar{Z}_{3} \bar{Z}_{4} \bar{Z}_{5} \bar{Z}_{6}
\end{gathered}
$$

and, in result, we obtain probabilistic operational risk model:

$P\left\{Y_{1}=1\right\}=P\left(Z_{1}\right)+P\left(Z_{2}\right)\left(1-P\left(Z_{1}\right)\right)+P\left(Z_{3}\right)\left(1-P\left(Z_{1}\right)\right)(1-$ $\left.P\left(Z_{2}\right)\right)+P\left(Z_{4}\right)\left(1-P\left(Z_{1}\right)\right)\left(1-P\left(Z_{2}\right)\right)\left(1-P\left(Z_{3}\right)\right)+P\left(Z_{5}\right)(1-$ $\left.P\left(Z_{1}\right)\right)\left(1-P\left(Z_{2}\right)\right)\left(1-P\left(Z_{3}\right)\right)\left(1-P\left(Z_{4}\right)\right) P\left(Z_{6}\right)\left(1-P\left(Z_{1}\right)\right)(1-$ $\left.P\left(Z_{2}\right)\right)\left(1-P\left(Z_{3}\right)\right)\left(1-P\left(Z_{4}\right)\right)\left(1-P\left(Z_{5}\right)\right) P\left(Z_{7}\right)\left(1-P\left(Z_{1}\right)\right)(1-$ $\left.P\left(Z_{2}\right)\right)\left(1-P\left(Z_{3}\right)\right)\left(1-P\left(Z_{4}\right)\right)\left(1-P\left(Z_{5}\right)\right)\left(1-P\left(Z_{6}\right)\right)$.

Probabilistic risk model for one business line permits calculate the probability of losses at this business line if probabilities of initiating events are known.

Such models are constructed for eight business lines to calculate probabilities of events $Y_{1}, \ldots, Y_{8}$.

Let construct probabilistic model for calculation of bank's operational risk. Operational risk of bank is logical sum of probabilities of losses at eight business lines.

Logical model of bank's operational risk in disjunctive normal form is following:

$Y=Y_{1} \vee Y_{2} \vee Y_{3} \vee Y_{4} \vee Y_{5} \vee Y_{6} \vee Y_{7} \vee Y_{8}$, where:

$Y$ - bank's operational risk,

$Y_{i}$ - event on $i$ bank's business-line, $i=1, \ldots, 8$.

We obtain probabilistic model from logical model by orthogonalization:

$$
\begin{gathered}
P\{Y=1\}=P_{1}+P_{2}\left(1-P_{1}\right)+\ldots+P_{8}\left(1-P_{1}\right)\left(1-P_{2}\right) \\
\left(1-P_{3}\right)\left(1-P_{4}\right)\left(1-P_{5}\right)\left(1-P_{6}\right)\left(1-P_{7}\right) .
\end{gathered}
$$

Note, this model can be applied for estimation of bank operational risk by the standardized approach with use of values $P\left(Y_{1}\right), P\left(Y_{2}\right), \ldots, P\left(Y_{8}\right)$ instead of coefficients $\beta$ in formula of capital reservation [10]. Such modified formula permits determine the volume of the capital for covering losses more precisely because it takes into account functioning features of the concrete bank in comparison with coefficients $\beta$, averaged on whole branch [10].

In practice, we don't need use classification of events, offered by Basel Committee. LP-models can be adopted for business lines and kinds of events in concrete bank. For example, in some Russian banks the additional ninth business line is used. Events, which were not classified on eight standard business lines, are referred to ninth business line. Basel Comittee recommends refer these events to line where the most profit is [10].

In general case, for calculation of economic capital we have to calculate probabilities $P_{i, j, k}$ and losses $L_{i, j, k}$ for every initiating event $Z_{i, j, k}$ by statistical data. Here:

$i=1,2, \ldots, 8-$ number of business line;

$j=1,2, \ldots, 7-$ kind of events;

$k=1,2, \ldots, \mathrm{N}_{\mathrm{j}}-$ initiating events indexes in $j$-kind of events:

$\mathrm{N}_{j}=2 \div 20-$ number of initiating events of the kind $j$.

Initiating events probabilities are calculated by formula:

$$
P_{i, j, k}=N_{i, j, k} / N,
$$

where: $N_{i, j, k}$ - the number of appearance of losses at business line $i$ due to reason $j$ and initiating event $k$; $\mathrm{N}$ - the number of operations at the business line of the bank in considered time interval.

Estimation of economic capital volume consists of two parts: expected and unexpected losses. Economic capital for expected losses $E L$ is calculated by statistics and can be obtained by summarizing of all losses per a year (true economic capital):

$$
E L=\sum_{i=1}^{8} \sum_{j=1}^{7} \sum_{k=1}^{N_{j}} L_{i, j, k},
$$

where $L_{i, j, k}$ - summarized losses due to realization (or several realization) event $k$ of kind $j$ at business line $i$ during report period (for example, one year).

Unexpected losses $U L^{L P}$ is suggested to estimate by formula of predictable damage for technical systems:

$$
U L^{L P}=P_{Y} L_{\max },
$$

where: $P_{Y}$ - operational risk of bank is calculated by equation (12),

$L_{\max }$ - maximal possible loss at business line, concrete operation (transaction) or in bank as a whole, depending from modeling level.

Risk-manager should decide what losses will be chosen as $L_{\max }$, proceed from the situation. Gross receipt at business line, maximal losses at business line or operation (transaction) can be chosen, or $L_{\max }$ can be given on basis of expert evaluation also. 
Economic capital volume is calculated by formula:

$$
R_{S u b}{ }^{L P}=E L+U L^{L P} .
$$

Value $R_{\text {sub }}{ }^{L P}$ is bottom limit of economic capital.

The basic indicator approach determines economic capital for operational risk of bank have to be $15 \%$ of average gross receipt of bank during three years [9]. For analysis we have to know top limit of possible losses from unfavorable economic situation and unforeseen rare events.

Top limit estimation of the reserved capital is performed proceed from the integrated risk of the bank as a whole:

$$
R_{\text {Sup }}{ }^{L P}=P_{Y} Q
$$

where: $Q-$ gross receipt of the bank; $P_{Y}-$ the probability calculated by probabilistic model (12).

Evaluations (14), (16) and (17) will be different. Choice of the formula depends on data and expenses of data obtaining. Formula (14) estimates real losses of last years. Formula (16) gives bottom limit of reserved capital under known losses. However, in practice it is difficult to estimate precisely the value of losses due to operational risk event, therefore, we need to know top limit of possible losses. In case of unstable economic and political situation we recommend use formula (17) for calculation of maximal economic capital, using the volume of bank's profit which can be lost in case of unfavorable events. Choice of formula depends on situation and this is duty of risk-manager.

\section{SECURITY PORTFOLIO MANAGEMENT}

The dissertation work by V. Alexeev is devoted to risk management of security portfolio [12].

Connection between parameters of risk and efficiency for security portfolio is presented at fig. 2 . Discrete distribution of probabilities for efficiency parameter $Y$ was constructed by database with $N$ states. Minimal admissible value of efficiency parameter is $Y_{a d}$. Dark area determines Risk as probability of state with efficiency less than admissible one.

Database (table 1) contains statistics about yield of portfolio's assets in different time. The number of columns is equal to number of assets in portfolio, the number of strings (states) reaches a few hundreds. Modification DB is following: the interval of yield's change for every asset $j$ is divided into $N_{j}$ subintervals. Casual event-grade $Z_{j r}$ corresponds to every state $r$ of asset $j$. So, DB is transforming into $\mathrm{KB}$.

To choice the optimal portfolio we need to determine shares of assets $x_{l}, \ldots, x_{j}, \ldots, x_{n}$ under optimization criteria:
1. Maximization of admissible portfolio yield $Y_{a d}$ under given risk Risk: $Y_{a d} \rightarrow \max ;$ Risk $=$ const.

2. Minimization Risk under given admissible yield $Y_{a d}:$ Risk $\rightarrow$ min; $Y_{a d}=$ const.

We suggest algorithms of optimization with casual search method and gradient method [8,9]. Following selected value of admissible portfolio yield $Y_{a d}$ are calculated (fig. 2):

- a number of states $N_{a d}$ in «tail» $\left(Y<Y_{a d}\right)$;

- portfolio risk Risk $=N_{a d} / N$, where $N$ is a number of portfolio's states in DB;

- a number of appearances of events-grades for every asset $N_{j r j}$ in all states of portfolio, where $r_{j}=1,2, \ldots, N_{j}$ are grades in asset $j$,

- probabilities of events-grades of assets, calculated by all states of portfolio $P_{j r j}=N_{j r j} /$ $N$

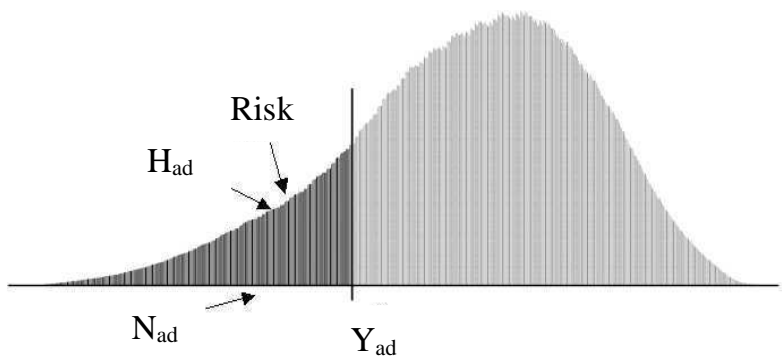

Figure 2. The histogram of yield distribution

Formula for calculation of state probability is [6]:

$$
p_{i}=P\left(Y_{i}\right)=p_{1 r l} \cdot \ldots \cdot p_{j r j} \ldots . p_{n r n}
$$

where $p_{1} r l, \ldots, p_{j} r j, \ldots, p_{n} r n$ are probabilities (frequencies) of corresponding events-grades of assets for portfolio's state $i$.

Let we know relative shares of capital $x_{1}, \ldots, x_{j}, \ldots, x_{n}$, invested in every asset $1,2, \ldots, n$. Calculation of contributions of grades are calculated by algorithmic way.

Contributions of events-grades in admissible portfolio yield $Y_{a d}$ are equal

$$
W_{j r}=\frac{N_{j r}}{N_{a d}}, \quad j=1,2, \ldots, n \quad ; \quad r=1,2, \ldots, N_{j},
$$

where $N_{a d}$ and $N_{j r}$ are numbers of all unfavourable states of portfolio in «tail» and number of states of portfolio containing grade $r$ of asset $j$ and satisfying to condition:

$$
Y<Y_{a d}
$$

Contributions of events -grades in Risk:

$$
C_{j r}=\frac{P_{j r}}{R i s k}, \quad j=1,2, \ldots, n ; \quad r=1,2, \ldots, N_{j},
$$


where $P_{j r}$ - is summarized probability of portfolio states with grade $r$ of asset $j$.

Grades, which have largest contributions, indicate the possibility of security failure. These contributions are basis for management of portfolio with replacing one assets by others or change of capital shares $x_{l}$, $x_{2}, \ldots x_{n}$, invested in portfolio.

By formula (18) we can calculate probabilities of all portfolio states and probabilities for not realized states, generating them by Monte-Carlo method. We can also calculate Risk of portfolio exactly, as sums of probabilities of portfolio's states in «tail».

Let set minimal admissible yield $Y_{a d}$ and make transition from VaR model (fig. 2) to LP risk model:

$$
\mathrm{Y}=\mathrm{Z}_{1} \vee \mathrm{Z}_{2} \vee \ldots \vee \mathrm{Z}_{\mathrm{j}} \vee \ldots \vee \mathrm{Z}_{\mathrm{n}}
$$

transform it in orthogonal form and write probabilistic risk model

$$
P\{Y\}=P_{1}+P_{2}\left(1-P_{1}\right)+\ldots .+P_{3}\left(1-P_{2}\right)\left(1-P_{1}\right)+\ldots .
$$

In (21) for every portfolio state we have to replace logical variables $\mathrm{Z}_{1}, \mathrm{Z}_{2}, \ldots \mathrm{Z}_{\mathrm{n}}$ by corresponding logical variables of their grades. In (22) for every portfolio state we have to place probabilities of events-grades correspondingly.

For determination of probabilities $P_{j r}, j=1,2, \ldots$ $n ; \quad r=1,2, \ldots, N_{j}$, which are placed in (23), we perform identification [8].

Research in security portfolio management. The portfolio management is regular change of shares of assets in accordance with optimization results. We had considered portfolio with 9 assets of large companies (Aeroflot, AutoVAZ, Norilsk Nickel, Irkutskenergo, Gazprom, Rostelecom, RAO UES, Sberbank, Tatneft). Primarily, the capital was distributed among assets in same shares. Time period is January 1, 2005 - December 31, 2005. 100-days long prehistory was selected. The portfolio was being optimized daily under risk minimization criterion for given value of yield. Also, risk and efficiency for not changed portfolio, RTS index and Sharpe ratio [13] (which indicates efficiency of management and demonstrates how portfolio yield can be justified by given value of risk) were calculated.

Results of calculated research under various $Y_{a d}$ are presented in table 2 .

Table 2. Probabilistic weights of events-assets in portfolio risk

\begin{tabular}{|l|l|l|l|l|l|}
\hline Asset & $\begin{array}{l}\text { Shar } \\
\text { e in } \\
\text { portf } \\
\text { olio, } \\
\%\end{array}$ & $\begin{array}{l}\mathrm{P}_{\mathrm{jm}} \\
\text { under } \\
\text { Risk } \\
=0 \%\end{array}$ & $\begin{array}{l}\mathrm{P}_{\mathrm{jm}} \\
\text { under } \\
\text { Risk } \\
=0,5 \%\end{array}$ & $\begin{array}{l}\mathrm{P}_{\mathrm{jm}} \text { under } \\
\text { Risk } \\
\%\end{array}$ & $\begin{array}{l}\mathrm{P}_{\mathrm{jm}} \text { under } \\
\text { Risk } \\
\%\end{array}$ \\
\hline $\begin{array}{l}\text { Rostele } \\
\text { com }\end{array}$ & 24,1 & 0,1317 & 0,1105 & 0,0491 & 0,0198 \\
\hline $\begin{array}{l}\text { RAO } \\
\text { UES }\end{array}$ & 36,3 & 0,2124 & 0,0933 & 0,0517 & 0,0229 \\
\hline $\begin{array}{l}\text { Sberba } \\
\text { nk }\end{array}$ & 21,6 & 0,1875 & 0,0727 & 0,0703 & 0.0349 \\
\hline Lukoil & 18,0 & 0,1431 & 01063 & 0,0636 & 0,0168 \\
\hline
\end{tabular}

Mainly, RAO UES assets are influencing on risk $0 \%$. The situation is another if we are increasing the risk. For example, risk more than $1 \%$ and $2 \%$ is caused by Sberbank assets mainly.

In result of analysis by weights of events we are determining most danger assets and their grades. These weights are used for portfolio management, replacing of one asset by other or changing shares $\mathrm{x}_{1}$, $\mathrm{x}_{2}, \ldots, \mathrm{x}_{\mathrm{n}}$ of invested capital.

\section{RISK MANAGEMENT IN RESTAURANT}

Management of risk and efficiency of restaurant (or profit of company) differs from security portfolio management because efficiency (yield) of portfolio is calculated for every state of portfolio (DB) but efficiency (profit) of the restaurant (company) is known by statistical data of DB.

Efficiency parameter (turnover per a day) $Y$ is considered as casual value that depends on parameters $Z$. Parameters $Z$ are presented by discrete values that are nominated as events-grades and designated by logical variables [6].

Daily statistics per calendar year was considered $(N=365$ days). State of restaurant is determined by following parameters and their grades:

$Z_{l}$ - a month, grades are $1,2, \ldots, 12$;

$Z_{2}$ - a day, grades are $1,2, \ldots, 7$

$Z_{3}$ - type of advertisement: 1 - for months $3, \ldots, 8$; 2 - for months $9, \ldots, 1,2$;

$Z_{4}$ - determines cooking team and depends on season and days of week: 1 - for months $9, \ldots, 12 ; 1$, 2 in days $1,2,3,4 ; 2$ - for months $9,10,11,12,1,2$ in days $5,6,7 ; 3$ - for months $3,4,5,6,7,8$ in days $1,2,3,4 ; 4$ - for months $3,4,5,6,7,8$ in days 5,6 , 7 ;

$Z_{5}$ - quality of personnel: 1 - inexperienced (2006 - for months 11, 12), 2 - average skills (2007 for months 1, 2, 3), 3 - experienced (2007 - for months $4, \ldots, 10)$;

$\mathrm{Z}_{6}$ - type of menu: $1-2006$, for months 11,12 (70 $\%$ usual menu plus $30 \%$ gourmet); $2-2007$, for months 1, $2(65+35 \%) ; 3-2007$, for months $3,4,5$ $(60+40 \%) ; 4-2007$, for months $6,7,8(55+45$ $\%) ; 5-2007$, for months $9,10(50+50 \%)$;

$Z_{7}$ - type of evening: 1 - usual; 2 - usual plus banquet; 3 - usual plus thematic; 4 - usual plus tasting.

For turnover of restaurant $Y$, the histogram of distribution of turnover with intervals on 25000 rubles was constructed. We had obtained 23 intervals or events-grades for efficiency parameter and calculated the number of days when turnover was within interval (the frequency). Monitoring of states of restaurant was performed during calendar year $(N=365$ days $)$ and, in average, $N / N_{y}=365 / 23=16$ states of restaurant were within every interval.

Following parameters are calculated under selected value of minimal admissible turnover $Y_{a d}$ : 
- a number of states of the restaurant $N_{a d}$, which are in «tail» $\left(Y<Y_{a d}\right)$;

- a risk of restaurant Risk $=N_{a d} / N$, where $N-$ is general number of states of restaurant in DB;

- a number of appearance of events-grades of every parameter $N_{j r j}$ in all states of restaurant, where $r_{j}=1,2, \ldots, N_{j}-$ are grades in parameter $j$;

- a number of appearance of events-grades of every parameter $N_{j r j}$ ad for states of restaurant which are in "tail" $\left(Y<Y_{a d}\right)$;

- probabilities of events-grades, which were calculated for all states of restaurant $P_{j r j}=N_{j r j}$ $/ N$

Formula for calculation of probability of $i$-state is:

$p_{i}=P\left(Y_{i}\right)=p_{1 r l} \cdot \ldots p_{j r j} \ldots . p_{n r n}, i=1,2, \ldots, N$.

where $\begin{array}{llllll}p_{1} r l & \ldots \cdot p_{j}{ }_{j} & \ldots \cdot p_{n} n-\text { are probabilities }\end{array}$ (frequencies) of corresponding events-grades of parameters for state $i$ of restaurant.

By formula (24) we are calculating probabilities of all states of restaurant which are presented in DB, and risk of not realized states of restaurant, generating them by Monte-Carlo method. Risk is calculated by (24) as sum of probabilities of states in "tail".

Contributions of events-grades in risk and efficiency of the restaurant are calculated simply. Contributions of parameters are calculated by method, described for security portfolio management.

Construction of LP-model of risk and efficiency of the restaurant provides the possibility to manage risk and efficiency of the restaurant [6].

We are constructing LP risk model for restaurant and determining probabilities of events-grades of parameters by identification method under statistical data. Calculations led to conclusions:

- Risk is different depending on month. Earlier months of restaurant's functioning are most risky $(11,12,1,2,3,4)$.

- Risk is also different depending on day. Friday and Saturday are less risky (grades 5, 6).

- Risk in both types of advertisement are same $(1,2)$.

- Risk due to various team $(1,4)$ differs almost twice.

- Risk due to qualification of personnel $(1,2,3)$ is same.

- Risk due to type of menu differs almost 25 times $(3,5)$. Five type menu is less risky.

- Risk due to type of evening changes almost 400 times (type 1 - usual - has largest risk, type 2 - with a banquet - has smallest risk).

Risk of efficiency parameter $Y$ is proportional to probabilities of parameters $Z$. Therefore, average values of probabilities $P_{j m}$ of grades of influencing parameters $Z$ can be considered as significances of parameters for average risk of efficiency parameter.

We can manage risk and efficiency of the restaurant by changing the type and quality of advertisement, menu, evening, and increasing qualification of personnel. This technology can be applied for another objects, shops, warehouses and enterprises.

\section{NARCOTIZATION RISK ESTIMATION}

The construction of indicative LP-model we are considering at example of socio-economic system for counteraction to narcotization. The aim of risk management is reduction large economical losses in State, caused by narcotism, and increasing of morality in society $[6,14]$.

The main difficulty of this problem is determination latency value of narcotism. It's supposed, about $10 \%$ population is inclined to narcotism; $80 \%$ population is in risk group and can be involved in narcotism; $10 \%$ population cannot become drug addict in any conditions. There is inverse relationship between narcotization latency and indicators.

LP-models of narcotization risk use DB from monitoring system. Narcotization indicators are constructed so that risk is growing with increasing of these indicators. Danger event is deviation of indicators from 0. Probability, the indicator $q_{i}$ is larger 0 , is:

$$
P\left\{q_{i} \geq 0\right\}=R_{i},
$$

This probability is risk $R_{i}$. Since indicators are normalized within $[0,1]$ so risk is equal to $R_{i}=q_{i}$.

Fundamental parameters, which demonstrate the narcotization rate in region [14], are divided into blocks $B_{1}, \quad B_{2}, \ldots, B_{7}$. They show efforts for counteraction to illegal drug trafficking (IDT) [14] and not determine risk of dangerous situation, which can be used to manage narcomania situation. Difficulty of model's construction is in latency of narcomania, namely, consumption soft drugs.

Latency estimation in IDT. In arrested parts of drugs, strong drugs are $10 \%$ and soft drugs are $90 \%$. About $10 \%$ drug addicts are registered, who are taking strong drugs and were identified by health authorities and after crimes. Drug addicts, who take soft drugs, are not registered although they cause potential threat to society. Latency of narcomania means: general number of drug addicts is beyond of control and this fact leads to difficulties in planning of measures for their reduction.

The latency is estimated by comparison of data about crimes, morbidities of drug addicts, opinion polls. The technique of latency coefficient estimation is described in [7, 14].

Indicators of narcotization. Fundamental parameters, which can be associated with concept of danger event, are initiating indicators also, that say 
about risk of narcotization. Identifiers of indicators are designated as $Y$.

Fundamental parameter «Narcoimmunity of territory» were been normalizing:

1. Human potential development index $\mathrm{Y}_{16}$ is normalized by the condition: if index is growing then risk of territory narcotization is reducing: $\mathrm{Y}_{16}=1 /\left(100 \bullet \mathrm{Y}_{16}\right)$.

2. Personal development index $\mathrm{Y}_{17}$ is normalized by the condition: if index is growing then risk of narcotization is reducing: $\mathrm{Y}_{17}=1 /(100 \bullet$ $\left.\mathrm{Y}_{17}\right)$.

3. Latency index $Y_{18}$ is normalized by the condition: if coefficient $K_{\text {lat }}$ is reducing then risk of narcotization is growing: $Y_{18}=1 / K_{\text {lat }}$.

Fundamental parameters of blocks 6 and 7 are used for calculation of narcomania latency coefficient on territory $K_{\text {lat }}$ and, further, corresponding latency indicator $Y_{18}$.

The measure of region narcotization danger is probability or risk. In LP-models all events have the sense of danger, that increase with each new event. In logical addition of events the risk (probability) is within interval $[0,1]$.

LP-model of narcotization danger considers following risks:

- probabilities of invalid events - indicators $Y$;

- probabilities of danger events, blocks of indicators $B$;

- probability of narkotization danger in region $Y$ and blocks $B$

- probability of narkotization with taking into account the narcomania latency $Y_{18}$.

Some fundamental parameters are const and not entered into model because their risk is equal to 0 and they cannot be used in management.

Derivative indicators and LP-model of narcotization risk. LP-model of narcotization danger in region is constructed under parameters in blocks $B_{1}, B_{2}, \ldots, B_{6}$. We imply these blocks as derivative indicators-events and logical variables.

Parameters $B_{1}, B_{2}, \ldots, B_{5}$, as derivative events are functions of corresponding identifiers $Y$. Probabilities of these events are within interval $[0,1]$. The probability is growing, the risk of narcotization danger in region is increasing. Derivative indicators are determined as logical risk functions:

for block-medical and biological parameters:

$B_{1}=Y_{23}=Y_{1} \vee Y_{2} \vee Y_{3} \vee Y_{4}$;

for block - crime rate in illegal drug trafficking:

$B_{2}=Y_{24}=Y_{5} \vee Y_{6} \vee Y_{7} \vee Y_{8} \vee Y_{9}$

for block - economic cost and damage:

$B_{3}=Y_{25}=Y_{10} \vee Y_{11} \vee Y_{12}$;

for block - population stability:

$B_{4}=Y_{26}=Y_{13} \vee Y_{14} \vee Y_{15}$;

for block - narcoimmunity of the territory:

$B_{5}=Y_{27}=Y_{16} \vee Y_{17}$

LP-model of risk of danger drug situation in region by parameters:

$$
\begin{aligned}
& B=Y_{29}=B_{1} \vee B_{2} \vee B_{3} \vee B_{4} \vee B_{5} ; \\
& \text { LP-model of risk of danger drug situation in }
\end{aligned}
$$
region by derivative indicators with taking into account the narcomania latency: $Y_{30}=Y_{28} \vee Y_{29}$.

Calculation research. The research was performed by data of monitoring of drug situation in Saint-Petersburg in 2012. The results of automated research on LP-model of risk of danger drug situation by indicators are presented. Indicators are given by numbers of their indexes.

Logical function of risk of danger drug situation is:

$$
\begin{aligned}
& Y_{30}=Y_{17} \vee Y_{16} \vee Y_{15} \vee Y_{14} \vee Y_{13} \vee Y_{12} \vee Y_{11} \vee Y_{10} \vee \\
& Y_{9} \vee Y_{8} \vee Y_{7} \vee \vee Y_{6} \vee Y_{5} \vee Y_{4} \vee Y_{3} \vee Y_{2} \vee Y_{1} \vee Y_{22} \vee \\
& Y_{21} \vee Y_{20} \vee Y_{19} \vee Y_{18 .}
\end{aligned}
$$

Probabilistic function of risk of danger drug situation was obtained after the orthogonalization of logical function. Probabilities of indicators $P$ and $Q=1-P$ have same indexes as logical variables. Probabilistic function of risk of danger drug situation in region is:

$$
P\left\{Y_{30}\right\}=P_{17}+P_{16 \cdot} Q_{17}+P_{15} \cdot Q_{16} \cdot Q_{17}+
$$

$P_{14} \cdot Q_{15} \cdot Q_{16} \cdot Q_{17}+\ldots . .+Q_{1} \cdot Q_{2} \cdot Q_{3} \cdot Q_{4} \cdot Q_{5} \cdot Q_{6} \cdot Q_{7} \cdot Q_{8} \cdot Q_{9}$ $Q_{10} \cdot Q_{11} \cdot Q_{12} \cdot Q_{13} \cdot Q_{14} \cdot Q_{15} \cdot Q_{16 \cdot} \cdot Q_{17} \cdot P_{18} \cdot Q_{19} \cdot Q_{20} \cdot Q_{21} \cdot Q_{22}$, where «.», «+» are operations of arithmetical multiplication and addition.

Probabilities of initiating events $Y_{1}-Y_{22}$ are given by monitoring results. Risk of drug situation danger in region by indicators with consideration of latency is equal $P\left\{Y_{30}\right\}=0,191852$. Risk of danger caused by narcomania latency only is equal $P\left\{Y_{28}\right\}=0,118389$. Risks of danger of blocks of indicators are following:

$P\left\{B_{1}\right\}=P\left\{Y_{23}\right\}=0,028 ; \quad P\left\{B_{2}\right\}=P\left\{Y_{24}\right\}=0,00849 ;$ $P\left\{B_{3}\right\}=P\left\{Y_{25}\right\}=0,01493 ; \quad P\left\{B_{4}\right\}=P\left\{Y_{26}\right\}=0,007449$; $P\left\{B_{5}\right\}=P\left\{Y_{27}\right\}=0,0264 ; P\{B\}=P\left\{Y_{29}\right\}=0,0833$.

\section{CONCLUSION}

As you see above, we have applied LP method to estimate and manage risk in various spheres of socioeconomic systems. Research was performed during 15 years and demonstrates the possibility to apply LP method but, in comparison with engineering, LP models are simple and, as a rule, have disjunctive normal form, corresponding to initial statistical data structure. Equation (7), (11), (22), (25) are same and equal to (2). But LP-models in economics can be more complex and based on risk scenario, e.g. the model of internal fraud in bank [15] or models bribery and corruption [6].

Of course, large volume of statistical data makes LP-model's application easier but the algorithm of identification is required. This is complex optimization task for multidimensional integer function having real arguments and many extremes [8].

LP-models allow calculate risk (probability of unfavourable event) and contributions of initiating 
Environment. Technology. Resources, Rezekne, Latvia Proceedings of the $11^{\text {th }}$ International Scientific and Practical Conference. Volume II, 58-66

events in risk. So, we can identify "weak" elements in system and try to reduce risk. Risk management is made by decision-making procedures proceed from contributions.

If there is no any statistics, we can use the method of summarized randomized indexes [16] and obtain estimations of probabilities by non-numeric, notexact and incomplete expert information.

Integration of LP-models, identification algorithm and method of summarized randomized indexes is powerful analytical tool for risk management and decision-making in complex socio-economic systems.

\section{REFERENCES}

[1] Порецкий П.С. Решение общей задачи теории вероятностей при помощи математической логики // Собрание протоколов заседаний секции физикоматематических наук общества естествоиспытателей при Казанском университете, Казань, 1887, Т.5, С. 83116.

[2] Бернштейн С.Н. Собрание сочинений. Т. 1-4, М, $1952-$ 1964

[3] Колмогоров А.Н. Общая теория меры и исчисление вероятностей // Труды Комму-нистической академии. Т 1. Математика, - M, 1929 г., С. 8-21.

[4] Гливенко В. И. Курс теории вероятностей. - М.: ГОНТИ, 1939.

[5] Рябинин И.А. Надежность и безопасность структурносложных систем//СПбГУ, 2007, 276 с.

[6] Solozhentsev E.D. Risk Management Technologies (with Logic and Probabilistic Models). Springer, 2013, 328 p.

[7] Hastie T., Tibshirani R., Friedman J. The Elements of Statistical Learning: Data Mining, Inference, and Prediction, Springer 2009, 764 p.
[8] Solojentsev E.D., Karasev V.V. Identification of Logic and Probabilistic Models of Risk in Structurally Complex Systems with Groups of Incompatible Events. - Automation and Remote Control, March 2002; Vol. 63, Issue 3, p. 433448.

[9] Karasev V.V. Monitoring and Crediting Process Control with Use of Logical and Probabilistic Risk Model / /International Journal of Risk Assessment and Management, Vol. 18, Nos 3\4, 2015, p. 276 - 287.

[10] 10.International Convergence of Capital Measurement and Capital Standards: A Revised Framework, Bank for International Settlements, Press \& Communications, CH4002 Basel, Switzerland, June 2004, 273 p.

[11] Karaseva E. Ability of Logical and Probabilistic Model for Operational Risk Management // Reliability: Theory \& Applications, N 3 (42), Vol. 11, September 2016, pp. 23-32.

[12] Алексеев В.В., Соложенцев Е.Д. Логико-вероятностное моделирование риска портфеля ценных бумаг.Информационно-управляющие системы, N 6(31). 2007. C. 49-56.

[13] Scholz, Hendrik (2007)."Refinements to the Sharpe ratio:Comparing alternatives for bear markets" Journal of Asset Management. 7 (5): 347-357.

[14] Solozhentsev E.D., Mityagin S. Logical and Probabilistic Risk Models for Assessment and Analysis of the Drug Addiction Problem in a Region. - International Journal of Risk Assessment and Management, 2015, Vol. 18, No.1. P. $1-17$.

[15] Карасева Е.И. Анализ вкладов событий в операционный риск банка // Научно-технические ведомости. Серия Экономика, № 3, 2012, с. 151-154.

[16] Karaseva E.I., Alexeev V.V. Synthesis and analysis of probabilities of events by non-numeric, inaccurate and incomplete expert information // International Journal of Risk Assessment and Management, Vol. 18, Nos 3\4, 2015. pp. $222-236$. 